\title{
Environmental SEM and dye penetration observation on resin-tooth interface using different light curing method
}

\author{
Takako YOSHIKAWA ${ }^{1}$, Makoto MORIGAMI², Alireza SADR ${ }^{3}$ and Junji TAGAMI ${ }^{1}$ \\ ${ }^{1}$ Cariology and Operative Dentistry, Department of Oral Health Sciences, Graduate School of Medical and Dental Sciences, Tokyo Medical and \\ Dental University (TMDU), 1-5-45 Yushima Bunkyo-ku, Tokyo 113-8549, Japan \\ ${ }^{2}$ Department of Dentistry, Toranomon Hospital, Minato-ku, Tokyo, Japan \\ ${ }^{3}$ IB3T Laboratory, Department of Restorative Dentistry, School of Dentistry, University of Washington, Seattle, WA, USA \\ Corresponding author, Takako YOSHIKAWA; E-mail: yoshikawa.ope@tmd.ac.jp
}

\begin{abstract}
The aim of this study was the effects of different light curing methods on marginal sealing and resin composite adaptation to the cavity wall using the dye penetration test and environmental scanning electron microscope (SEM) observations. Cylindrical cavities were prepared on cervical regions. The teeth were restored with Clearfil Liner Bond $2 \mathrm{~V}$ adhesive and filled with Clearfil Photo Bright or Palfique Estelite resin composites. These resins were cured with a conventional light-curing method or a slow-start curing method. After thermal cycling, the specimens were subjected to the dye penetration test to evaluate marginal sealing and adaptation of the resin composites to the cavity walls. These resin-tooth interfaces were then observed using environmental SEM. The light-cured resin composite, which exhibited increased contrast ratios during polymerization, suggests high compensation for polymerization stress using the slow-start curing method. There was a high correlation between dye penetration test and environmental SEM observation.
\end{abstract}

Keywords: Environmental SEM, Dye penetration test, Polymerization, Resin composite, Adaptation

\section{INTRODUCTION}

Resin composite polymerization results in volumetric shrinkage, also known as polymerization shrinkage, and the stress created results in greater gap formation between the resin and cavity wall ${ }^{1-4}$. These marginal gaps and subsequent microleakage may cause marginal staining, postoperative sensitivity ${ }^{5,6)}$, and secondary caries. In addition, gap formation between the restoration and cavity wall may result in pain on biting and adhesion failure after repeated occlusal loading. Light-cured resin composites are widely used in clinical practice because of their esthetic advantages, ease of use, good bonding to tooth structures, and excellent mechanical properties.

The polymerization reaction for light-cured composites is rapid, which results in the development of higher stresses in the cured materials compared with those in self-activated materials ${ }^{7}$. Furthermore, the maximum interfacial stress generated at the wall of a cavity filled with light-cured composites is twice that generated with self-cured composites ${ }^{8)}$. Therefore, gap formation between the resin and cavity wall caused by this stress is greater when light-cured materials are used than when self-cured materials are used ${ }^{11}$. In addition, when the bond strength exceeds these polymerization stresses, a crack is initiated in the tooth structure, generally enamel ${ }^{1,9-12)}$, resulting in direct contact of the restoration with saliva and bacteria.

There are several ways to overcome the curing stresses generated by light-cured, bulk-filled resin composites. One technique for decreasing curing stresses is the use of a flowable resin composite as a lining material ${ }^{13,14}$. The low elastic modulus and shrinkage stress contributes to improved resin composite adaptation to the cavity wall ${ }^{15,16}$. However, the decreased mechanical properties of flowable composite materials decrease the bond strength to the dentin wall ${ }^{17,18)}$.

The incremental filling technique is used by many clinicians ${ }^{19}$. This technique is thought to decrease the curing stress at the tooth-resin interface, which occurs when a cavity is bulk-filled with light-cured resin composites. However, in a theoretical study using finite element analysis, it was reported that the incremental filling technique could produce greater polymerization shrinkage at the restoration-enamel interface compared with the bulk filling technique ${ }^{20}$. In addition, Yoshikawa et al. ${ }^{21)}$ demonstrated that incremental filling could not improve the bond strength to the floor of a box-like cavity.

Alternatively, increasing the speed of a light-cured resin composite caused decreased composite adaptation to the cavity wall when a resin composite of a different composition was used ${ }^{22}$. Composite flow decreased the amount of tensile force exerted by the hardening resin; therefore, the polymerization rate significantly affected strain development. The internal hardness of cured resins increased with argon ion laser output along with increasing intensity, although the maximum hardness was not always increased ${ }^{23)}$. The use of an intense light source may result in more frequent gap formation ${ }^{3,4,24-27)}$ When a composite was cured with an initial lowintensity light followed by a high-intensity light, an excellent marginal seal and cavity adaptation were achieved ${ }^{3,4,23,27,28)}$ Previous studies showed that when a composite was light-cured with an initial light intensity 
of $270 \mathrm{~mW} / \mathrm{cm}^{2}$ for $10 \mathrm{~s}$, followed by curing with a light intensity of $600 \mathrm{~mW} / \mathrm{cm}^{2}$ for $50 \mathrm{~s}$ after a 5 -s interval, the curing stress in the composite decreased ${ }^{3,4)}$ This method was termed the slow-start curing method ${ }^{28,29)}$

Furthermore, it is often difficult to observe real enamel cracks without damage because the enamel prisms are very fragile ${ }^{30)}$ Scanning electro microscope (SEM) observations require that specimens be absolutely dry. Therefore, enamel cracks are usually observed with a stereomicroscope $\mathrm{e}^{1,10,31,32)}$ and replica-

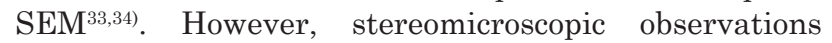
and impression making to create a replica also require dry specimen surfaces. These dry conditions promote enamel crack formation. In addition, observation of the resin-dentin interface is more difficult than that of the resin-enamel interface.

Because dentin comprises a significant amount of water, it is more sensitive to environmental conditions and shrinks under dry conditions. Cryo-SEM observations do not require dry conditions. However, cryo-SEM observations require complicated handling and time-consuming specimen preparation ${ }^{35}$. Alternatively, environmental SEM observations can be used to observe liquid and hydrated specimens such as native plants and living insects. In these cases, in order to maintain water in its liquid phase, a minimum water vapor pressure of $609 \mathrm{~Pa}$ is required at $0^{\circ} \mathrm{C}$, and this pressure can be arbitrarily chosen for the required indication. Therefore, environmental SEM observations require a lower pressure compared with conventional SEM observations, at least in terms of the pressure required to observe distilled water. However, environmental SEM equipment is very expensive and the observation technique is time-consuming. In comparison, the dye penetration test is an easy, rapid technique to observe resin composite adaptation to the cavity wall.

We hypothesized the following:

a) Slow-start curing methods would improve adaptation of resin composite restorations to the cavity walls.

b) The dye penetration test results would be correlated with environmental SEM observations.

\section{MATERIALS AND METHODS}

\section{Specimen preparation}

The materials, components, manufacturers, batch numbers, and bonding procedures used in this study are listed in Table 1. Erupted intact human molars were used after extraction and collected under our protocol No. 725, which was approved by the appropriate institutional review board. Cylindrical cavities with $2 / 3$ enamel and 1/3 dentin margins, a 2-mm depth, a $3-\mathrm{mm}$ diameter, and a C-factor of 3.7 were prepared on the buccal or lingual cervical regions of each molar (Fig. 1) using hand preparation with a diamond point (\# B12, GC, Tokyo, Japan) under copious air-water irrigation.

Each of 32 cavities was treated with the adhesive Clearfil Liner Bond $2 \mathrm{~V}$ (Table 1). After this adhesive

Table 1 Study materials

\begin{tabular}{|c|c|c|c|}
\hline Material/Manufacture & Components & Batch No. & Bonding Instruction \\
\hline \multirow{3}{*}{$\begin{array}{l}\text { Clearfil Liner Bond } 2 \mathrm{~V} \\
\text { (Kuraray Noritake Dental, } \\
\text { Tokyo, Japan) }\end{array}$} & $\begin{array}{l}\text { Primer A: MDP, HEMA, dimethacrylates, } \\
\text { photoinitiator, water, others }\end{array}$ & $00002 \mathrm{~A}$ & $\mathrm{a}, \mathrm{b}, \mathrm{c}, \mathrm{d}, \mathrm{e}, \mathrm{f}$ \\
\hline & $\begin{array}{l}\text { Primer B: HEMA, dimethacrylates, } \\
\text { accelerator, water }\end{array}$ & $00002 \mathrm{~A}$ & \\
\hline & $\begin{array}{c}\text { Bond A: MDP, HEMA, } \\
\text { Bis-GMA, dimethacrylates, } \\
\text { photoinitiator, microfiller, others }\end{array}$ & 00003A & \\
\hline $\begin{array}{l}\text { Clearfil Photo Bright } \\
\text { (Kuraray Noritake Dental) } \\
\text { Shade (US) }\end{array}$ & $\begin{array}{c}\text { silanated colloidal silica, prepolymerized } \\
\text { organic filler containing colloidal silica, } \\
\text { Bis-GMA, dimethacrylates, } \\
\text { photoinitiator, others } \\
\text { Filler load: } 82 \text { weight } \%\end{array}$ & 0036 & \\
\hline $\begin{array}{l}\text { Palfique Estelite } \\
\text { (Tokuyama Dental, Tokyo, } \\
\text { Japan) } \\
\text { Shade (A3) }\end{array}$ & $\begin{array}{c}\text { Silica-zirconia filler, } \\
\text { Bis-GMA, TEGDMA, } \\
\text { photo initiator } \\
\text { Filler load: } 82 \text { weight\% }\end{array}$ & 15597 & \\
\hline
\end{tabular}

MDP: 10 methacryloyloxydecyl dihydrogen phosphate, HEMA: 2-hydroxyethylmethacrylate, Bis-GMA: Bisphenol a diglycidylmethacrylate, TEGDMA: Triethyleneglycol Dimethacrylate.

a: mix equal volumes of primer A and B, b: apply primer for $30 \mathrm{~s}$, c: dry with gentle air blowing, d: apply adhesive, e: gently air-blow, f: light cure for $20 \mathrm{~s}$. 
was cured, the cavities were bulk-filled with Clearfil Photo Bright resin composite or Palfique Estelite resin composite. The resin composites were then polymerized by the conventional light curing method $\left(600 \mathrm{~mW} / \mathrm{cm}^{2}\right.$ for $60 \mathrm{~s})$ or the slow-start curing method $(270 \mathrm{~mW} /$ $\mathrm{cm}^{2}$ for $10 \mathrm{~s}+5$-s interval $+600 \mathrm{~mW} / \mathrm{cm}^{2}$ for $50 \mathrm{~s}$ ). An experimental quartz-tungsten halogen light curing unit (GC) that was connected to a slide regulator was used. This light curing unit had a control system for lamp voltage and adjustable light intensity, which was measured using a curing radiometer (model 100, Demetron Research, Danbury, CT, USA). The tip of light guide contacted to the cavity surfaces. After light curing, the specimens were stored in the dark for 24 $\mathrm{h}$ in water maintained at $37^{\circ} \mathrm{C}$. The restorations were finished and polished using wet 600 -grit $\mathrm{SiC}$ paper. The specimens were thermocycled for 500 cycles between $5^{\circ} \mathrm{C}$ and $55^{\circ} \mathrm{C}$, with a 30 -s dwell time.

\section{Marginal seal and cavity wall adaptation}

We used the dye penetration test to determine the degree of adaptation to the cavity margins and walls. This dye penetration test was performed by placing a 1.0\% acid red propylene glycol solution (Caries Detector, Kuraray Noritake Dental, Tokyo, Japan) at the margin of the restoration for $5 \mathrm{~s}$, followed by rinsing with water and gentle blow-drying. The extent of dye penetration was observed with a stereomicroscope (20× magnification). A photographic record of each specimen was acquired at
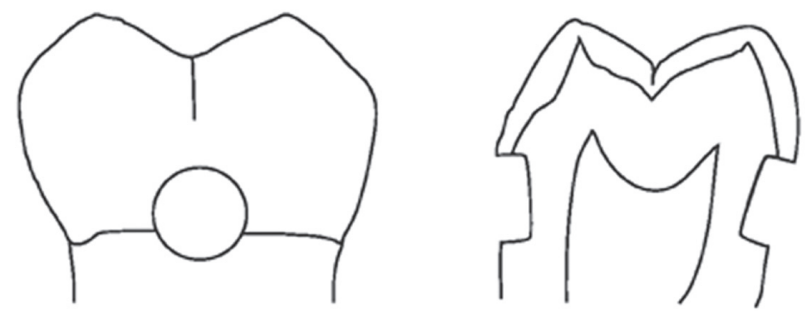

Fig. 1 Preparation of bonding substrate. this stage.

The specimens were then longitudinally cut in half using a diamond saw microtome (Leitz 1600 Saw Microtome, Ernst Leitz, Wetzlar, Germany) under running water, the dye was reapplied to the section, and images were acquired to observe gaps. In these images, the extent (length) of dye penetration along the cavity margins and walls was measured using a digitizer (KD4300 model, Graphtec, Tokyo, Japan). Areas of marginal dye penetration in the enamel were considered to be enamel cracks. The degree of marginal enamel crack formation was then determined as the ratio of the margin stained with the dye divided by the total length of the enamel cavity margin, which was converted to a percentage. The degree of dentin marginal leakage was determined as the extent (length) of dye penetration as a percentage of the total length of the dentin cavity margin. Dye penetration along the cavity walls was calculated as a percentage of the total cavity wall length. This area was referred to as the cavity wall-resin gap. The dye penetration test scores were compared using the Mann-Whitney U and Kruskal-Wallis tests.

Finally, the resin-tooth interfaces were observed using an environmental SEM (XL 30, FEG model, Philips, Eindhoven, the Netherlands) under conditions of saturated water vapor pressure of $609 \mathrm{~Pa}$. We also assessed the relationship between dye penetration test scores and environmental SEM observations.

\section{RESULTS}

Marginal leakage, cavity-wall gap formation, and enamel crack formation

Table 2 shows the results for enamel crack formation, marginal leakage, and cavity-wall gap formation. Photographic and environmental SEM observations for the sample specimens are shown in Figs. 2a to 7. Light curing using the slow-start curing method showed a complete dentin marginal seal when both Clearfil Photo Bright and Palfique Estelite resin composites were used. This method also result in significantly better cavity wall adaptation compared with that achieved with the

Table 2 Enamel crack formation, dentin marginal leakage and cavity-wall gap formation

\begin{tabular}{|c|c|c|c|c|c|c|}
\hline \multirow[b]{2}{*}{ Light curing method } & \multicolumn{3}{|c|}{ Clearfil Photo Bright } & \multicolumn{3}{|c|}{ Palfique Estelite } \\
\hline & $\begin{array}{l}\text { Enamel } \\
\text { crack }\end{array}$ & $\begin{array}{l}\text { Dentin } \\
\text { marginal } \\
\text { leakage }\end{array}$ & $\begin{array}{c}\text { Dentin } \\
\text { cavity-wall } \\
\text { gap formation }\end{array}$ & $\begin{array}{l}\text { Enamel } \\
\text { crack }\end{array}$ & $\begin{array}{l}\text { Dentin } \\
\text { marginal } \\
\text { leakage }\end{array}$ & $\begin{array}{c}\text { Dentin } \\
\text { cavity-wall } \\
\text { gap formation }\end{array}$ \\
\hline $600 \mathrm{~mW} / \mathrm{cm}^{2} 60 \mathrm{~s}$ & $65.0(39.4)$ & $38.5(30.9)^{\mathrm{a}, \mathrm{A}}$ & $41.5(11.0)^{\mathrm{b}}$ & $88.4(13.3)$ & $7.7(14.4)^{\mathrm{A}}$ & $39.7(13.9)^{\mathrm{c}}$ \\
\hline $\begin{array}{l}270 \mathrm{~mW} / \mathrm{cm}^{2} 10 \mathrm{~s}+5-\mathrm{s} \\
\left(\text { interval) }+600 \mathrm{~m} \mathrm{~W} / \mathrm{cm}^{2} 50 \mathrm{~s}\right.\end{array}$ & $75.7(26.1)$ & $0^{\mathrm{a}}$ & $14.1(11.3)^{\mathrm{b}}$ & $90.8(15.4)$ & 0 & $19.1(14.6)^{c}$ \\
\hline
\end{tabular}

$[\%$ : mean $(\mathrm{SD})]$

a Intergroup data designated with same superscript small letters each light-curing method are significantly different $(p<0.05)$.

${ }^{\mathrm{b}}$ Intergroup data designated with same superscript capital letters each resin composite are significantly different $(p<0.05)$. 


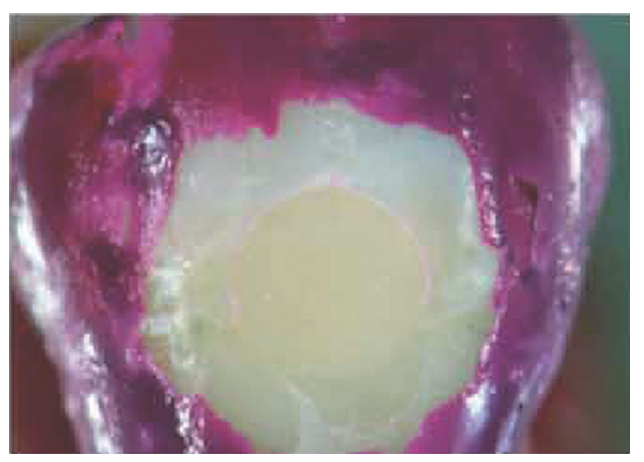

(a)

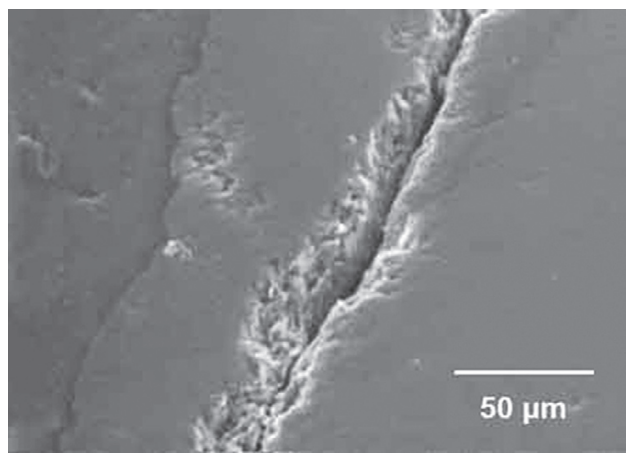

(b)

Fig. 2 (a) Photographic image of enamel cracks on the margins around Palfique Estelite resin composite restorations $(2 \times)$ placed using the conventional curing method.

(b)Environmental SEM observation of enamel cracks on the margins around Palfique Estelite resin composite restorations (500×) using the conventional curing method.

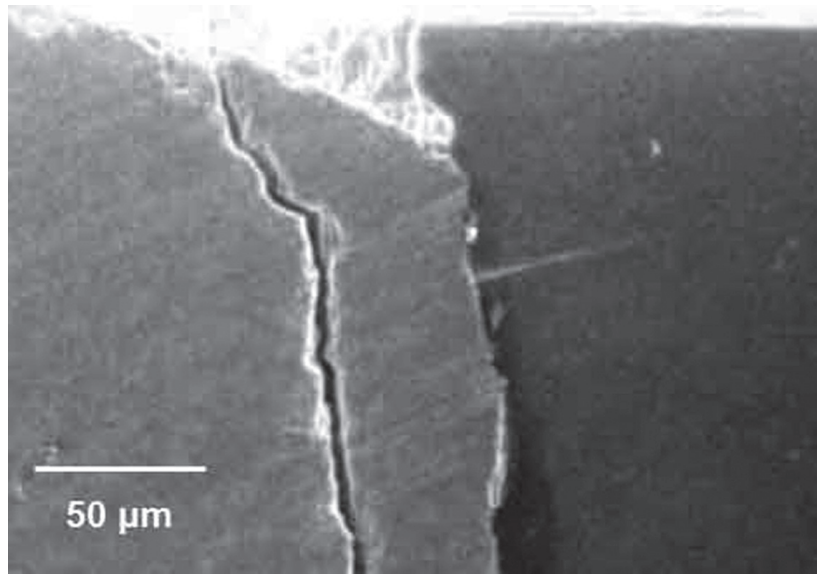

Fig. 3 Environmental SEM observation of enamel cracks on the cut surface around Palfique Estelite resin composite restorations (500×) using the slow-start curing method.

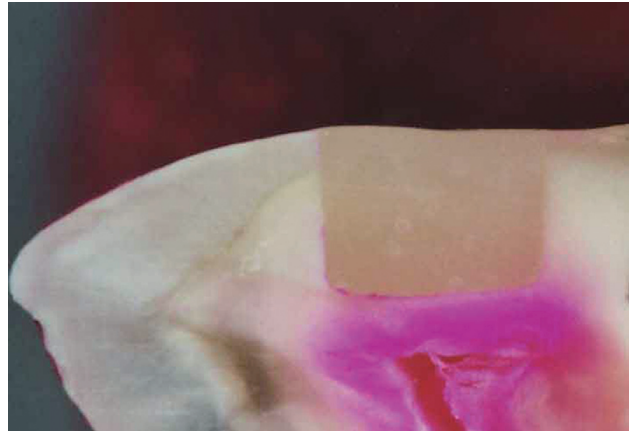

(a)

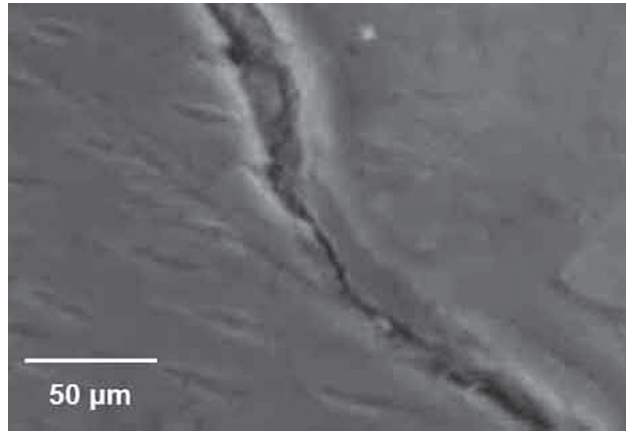

(b)

Fig. 4 (a) Photographic image of cavity-wall gap formation in a tooth restored with Palfique Estelite $(2 \times)$ using the conventional curing method.

(b) Environmental SEM observations of cavity-wall gap formation in a tooth restored with Palfique Estelite (500x) using the conventional curing method. 
conventional method for both resin composites $(p<0.05)$. Furthermore, the slow-start curing method resulted in a significantly better marginal seal when Clearfil Photo Bright was used compared with that achieved when the conventional curing method $(p<0.05)$ was used, which resulted in a poor dentin marginal seal and poor wall adaptation.

Enamel crack formation was observed in all specimens. In all groups, enamel crack formation appeared as a white margin on color image (Fig. 2a) on a surface that represented cracks in the enamel surrounding the resin composite restorations; these cracks were located at 30-50 $\mu \mathrm{m}$ from the resin-enamel interface on environmental SEM observations (Figs. $2 \mathrm{~b}$ and 3 ). There were no significant differences in the degree of enamel crack formation between the two curing methods $(p>0.05)$.

Figure $4 \mathrm{a}$ shows color image of a cutting surface obtained after curing Palfique Estelite using the conventional curing method. Figure $4 \mathrm{~b}$ shows environmental SEM image of this gap formation at the line angle between the cavity wall and floor. Gap formation was well correlated with the extent of dye penetration (Fig. 4a).

Figure 5a shows color image of a cutting surface obtained after curing Palfique Estelite the slow-start curing method. Figure 5b shows an environmental SEM image of a cutting surface obtained after curing Palfique Estelite using the slow-start curing method. This shows good dentinal adaption of the resin at the cavity floor line angle, consistent with the lack of dye penetration test (Fig. 5a).

Figure $6 \mathrm{a}$ shows color image of a cutting surface obtained after curing Palfique Estelite using the conventional curing method. Figure $6 \mathrm{~b}$ shows environmental SEM images of a cutting surface obtained

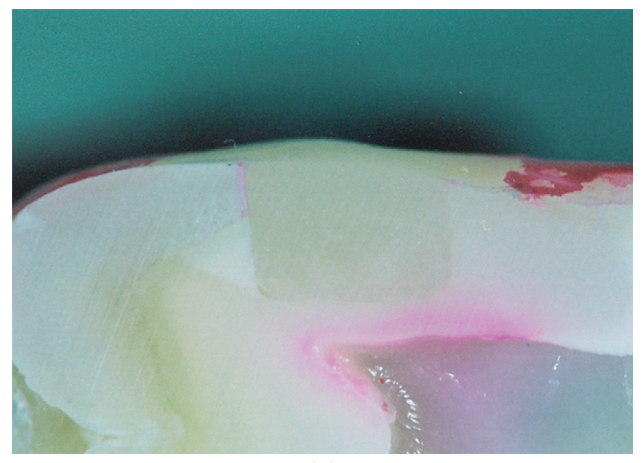

(a)

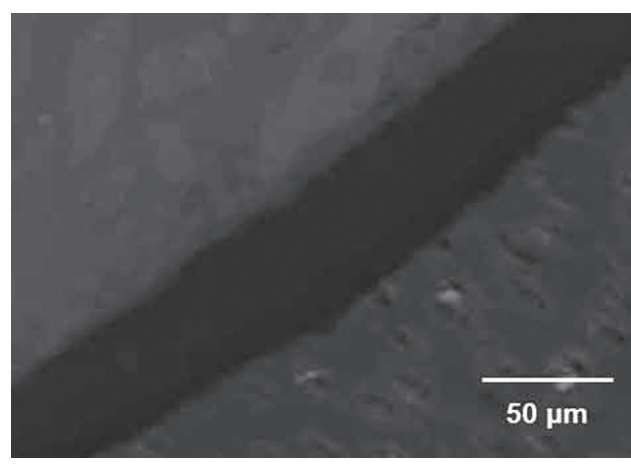

(b)

Fig. 5 (a) Photographic image of cavity wall-resin gap formation in a tooth restored with Palfique Estelite $(2 \times)$ the slow-start curing method.

(b) Environmental SEM observations of cavity wall-resin gap formation in a tooth restored with Palfique Estelite (500x) using the slow-start curing method.

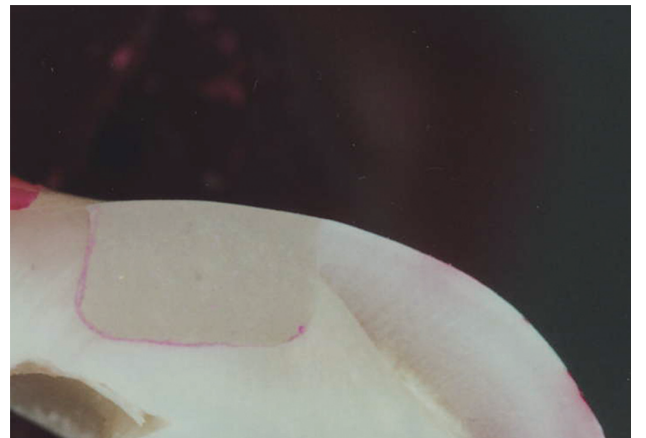

(a)

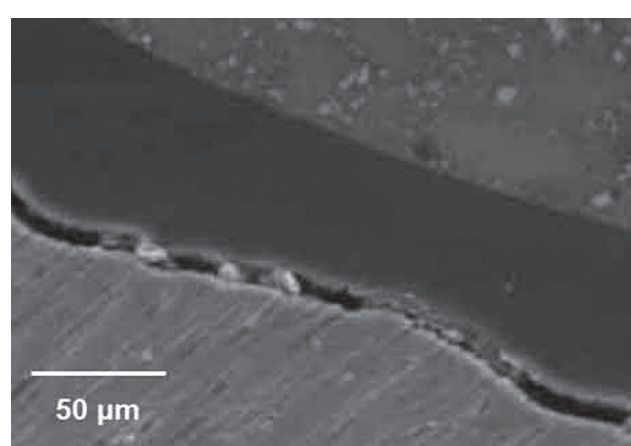

(b)

Fig. 6 (a) Photographic image of cavity-wall gap formation in a tooth restored with Clearfil Photo Bright $(2 \times)$ using the conventional curing method.

(b) Environmental SEM observations of cavity-wall gap formation in a tooth restored with Clearfil Photo Bright (500x) using the conventional curing method. 


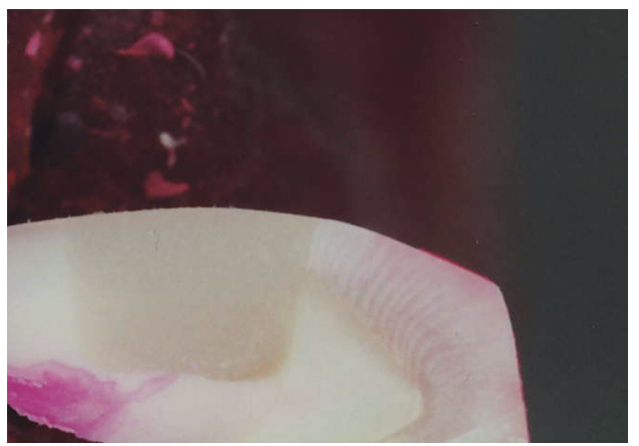

(a)

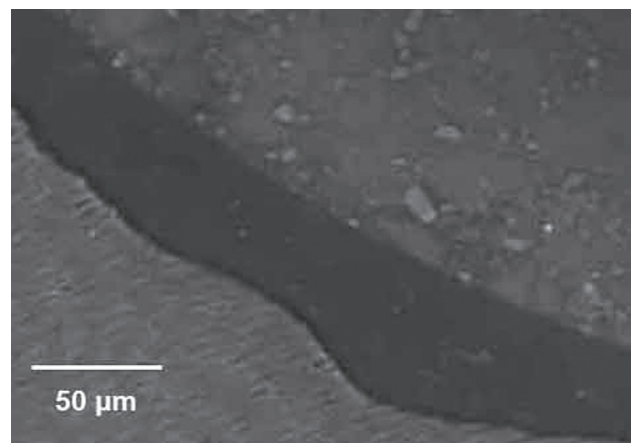

(b)

Fig. 7 (a) Photographic image of cavity-wall gap formation in a tooth restored with Clearfil Photo Bright $(2 \times)$ using the slow-start curing method.

(b) Environmental SEM observations of cavity-wall gap formation in a tooth restored with Clearfil Photo Bright (500x) using the slow-start curing method.

after curing Palfique Estelite using the conventional curing method. These show gap formation at the line angle between the cavity wall and floor. Gap formation was well correlated with the extent of dye penetration (Fig. 6a).

Figure $7 \mathrm{a}$ shows color image of a cutting surface obtained after curing Clearfil Photo Bright using the slow-start curing method. Figure $7 \mathrm{~b}$ shows an environmental SEM image of a cutting surface obtained after curing Clearfil Photo Bright using the slow-start curing method. This shows good dentinal adaption of the resin at the cavity floor line angle, consistent with the lack of dye penetration (Fig. 7a).

\section{DISCUSSION}

In this study, the conventional light curing method resulted in poor dentin marginal sealing and dentinal cavity wall adaptation, whereas the slow-start lightcuring method resulted in a complete dentin marginal seal with both Clearfil Photo Bright and Palfique Estelite resin composites. The slow-start method also resulted in significantly better dentinal cavity wall adaptation with both resin composites compared with the conventional method.

The curing pattern of light-cured composite resins has several disadvantages that may compromise the ability to achieve an excellent seal along the cavity wall, such as the direction and speed of polymerization shrinkage, depth of curing, and polymerization stress. A previous report ${ }^{27)}$ indicated that, at a certain light intensity, the amount of activated starter radicals was optimal to form cross-linked, long-chain molecules. A higher concentration of radicals stopped a reaction earlier than short-chain molecules did, suggesting that curing with a high-intensity light was more likely to result in marginal gaps and poor adaptation of resin composite to the cavity wall.

Polymerization shrinkage that occurs after gelation or curing results in the build-up of large stresses in a resin composite ${ }^{36)}$. Conversely, a decreased rate of surface hardness development due to a prolonged gel state and the accompanying absence of dye penetration suggest that this particular protocol results in increased material flow, which provides for stress relief despite the high elastic modulus and photosensitivity of the resin composite examined ${ }^{10)}$. Previous studies have shown that, when a composite was light-cured using the slowstart curing method, the resin hardened earlier at the cavity base than at the surface $e^{4,15,37)}$. According to the results of our previous report ${ }^{4)}$, the time required for complete polymerization shrinkage after the slow-start curing method was 2 min, which was less than half that after the conventional curing method.

However, the slow-start curing method resulted in a lower microhardness compared with the conventional curing method until $5 \mathrm{~min}$ from the start of curing. The viscosity of resin composite until $40 \mathrm{~s}$ from the start of curing was lower when initial low-intensity curing followed by high-intensity curing was used than when only high-intensity curing was used ${ }^{38)}$. The use of a light intensity that was lower than the maximum resulted in a significant decrease in polymerization stress without significantly affecting the degree of conversion ${ }^{39}$. This allowed for most of the resin composite polymerization shrinkage to occur during the initial flowable stage.

This method decreases polymerization shrinkage ${ }^{40)}$ and curing stresses by delaying the hardening of the resin composite and provides more time for relief from the stress induced by polymerization shrinkage ${ }^{4,28)}$. Moreover, the curing rate for resin that is directly adjacent to the cavity wall may be enhanced by free radicals that are already present in the bonding resin. An initial low light intensity was thought to enhance the polymerization rate at this location, rather than at the resin surface. The process of polymerization is then completed by high-intensity radiation, which allows for more uniform curing throughout the bulk of 
the resin composite. This radiation allows most of the polymerization shrinkage to occur during the initial flowable stage of the resin composite, thus enabling the resin to flow toward the cavity walls ${ }^{4}$.

When the slow-start curing method was used, the dentin marginal seal was significantly better when Clearfil Photo Bright resin was used than when the conventional curing method was used. Light transmission through light-cured resin composites is strongly affected by the opacity. This opacity is different before and after curing, and it is reflected by its contrast ratio ${ }^{40}$. This ratio decreases as the transparency of the resin composite increases. The contrast ratio for a completely opaque material is 1 , while that for a translucent material is $0-1^{40}$. Almost all resin composite materials have the property of decreasing the contrast ratio (increased transparency) during polymerization ${ }^{41)}$.

The contrast ratio of Clearfil Photo Bright increases during polymerization (increasing opacity), whereas that of Palfique Estelite slightly decreases during polymerization (slightly increased transparency) ${ }^{40}$. Therefore, when Clearfil Photo Bright is used, the delay in hardening of the resin composite, particularly at the top surface ${ }^{37}$, may apparently decrease curing stresses and allow more time for relief from the stress induced by polymerization shrinkage. This allows most of the polymerization shrinkage to occur during the initial flowable stage of polymerization, thus enabling the resin to flow within itself and preventing it from pulling away from the marginal cavity walls $\mathbf{s}^{4,15}$.

We also observed enamel crack formation in all of our specimens. However, there were no significant differences between the slow-start method and the conventional method in terms of the degree of enamel crack formation. Enamel is a highly mineralized tissue, with a modulus of elasticity greater than that of dentin. Enamel prisms are very fragile; the tensile strength of enamel is under $10 \mathrm{MPa}$ when pulled vertical to these enamel prisms ${ }^{30)}$. The enamel cavosurface reportedly exhibits disruption, even with a decreased power density of $100 \mathrm{~mW} / \mathrm{cm}^{10)}$. Therefore, enamel crack formation could not be avoided, even with the slow-start curing method, when the cavities were prepared with buttjoint margins. Further research is required to determine measures for preventing enamel crack initiation and propagation.

When attempting to predict the longevity of resin composite restorations using in vitro evaluations, it is important to simultaneously evaluate both marginal sealing and cavity wall adaptation. Environmental SEM observations demonstrated that the dye penetration test was useful and reproducible for evaluating marginal sealing and adaptation. Further research is also required to confirm the usefulness of this curing method for other resin composite filling materials in association with various dentin bonding systems, which may or may not act as stress-absorbing materials. The dye penetration test using a caries detector is easy to perform and accurately evaluates marginal sealing and resin composite adaptation to the cavity wall. This test can be used to evaluate resin composite adaptation to the cavity wall both in vitro and in vivo.

\section{CONCLUSIONS}

The slow-start curing method improved resin composite adaptation to the cavity wall and resulted in a complete marginal seal. The light-cured resin composite, which exhibited increased contrast ratios during polymerization, suggests high compensation for polymerization stress using the slow-start curing method. There was a high correlation between dye penetration test and environmental SEM observation.

\section{ACKNOWLEDGMENTS}

This work was supported by a Grant-in-Aid for Scientific Research No. 12307043 from the Ministry of Education, Science, Sports, Culture and Technology, Japan; a Grant-in-Aid No. 22592115, No. 25462950 from the Japan Society for the Promotion; and the Global Center of Excellence (GCOE) Program; the International Research Center for Molecular Science in Tooth and Bone Diseases.

\section{REFERENCES}

1) Yoshikawa T, Takatsu T, Hosoda H. Study on marginal integrity of the composite resin restorations: In relation to curing environment and morphological nature of surrounding dentin. Jpn J Conserv Dent 1989; 32: 639-655.

2) Ciucchi B, Bouillaguet S, Delaloye M, Holz J. Volume of the internal gap formation under composite restoration in vitro. J Dent 1997; 25: 305-312.

3) Yoshikawa T. The effect of curing method and environment on the marginal sealing and wall adaptation of composite restoration. Jpn J Conserv Dent 1997; 40: 1296-1323.

4) Yoshikawa T, Burrow MF, Tagami J. A light curing method for improving marginal sealing and cavity wall adaptation of resin composite restorations. Dent Mater 2001; 17: 359-366.

5) Eriksen HM, Leidal TI. Monkey pulpal response to composite resin restorations in cavities treated with various cleansing agents. Scand J Dent Res 1979; 87: 309-317.

6) Opdam NJ, Feilzer AJ, Roeters JJ, Smale I. Class I occlusal composite resin restorations: in vivo post-operative sensitivity, wall adaptation and microleakage. Am J Dent 1998; 11: 229234.

7) Feilzer AJ, de Gee AJ, Davidson CL. Setting stress in composite for two different curing modes. Dent Mater 1993; 9: 2-5.

8) Kinomoto Y, Torii M, Takeshige F, Ebisu S. Comparison of polymerization contraction stresses between self-and lightcuring composites. J Dent 1999; 27: 383-389.

9) Jørgensen KD, Asmussen E, Shimokobe H. Enamel damages caused by contracting restorative resins. Scand J Dent Res 1975; 83: 120-122.

10) Kanca J, Suh BI. Pulse activation: Reducing resin-based composite contraction stresses at the enamel cavosurface margins. Am J Dent 1999; 12: 107-112.

11) Yoshikawa T, Morigami M, Tagami J. Environmental SEM observation on resin-tooth interface using slow-start curing method. J Dent Res 2000; 79: 148 (Abstr 38).

12) Haak R, Wicht MJ, Noack MJ. Marginal and internal adaptation of extended class I restorations lined with flowable 
composites. J Dent 2003; 31: 231-239.

13) Ferdianakis K. Microleakage reduction from newer esthetic restorative materials in permanent molars. J Clin Pediatr Dent 1998; 22: 221-229.

14) Belli S, Inokoshi S, Ozer F, Pereira PN, Ogata M, Tagami J. The effect of additional enamel etching and a flowable composite to the interfacial integrity of Class II adhesive composite restorations. Oper Dent 2001; 26: 70-75.

15) Yoshikawa T, Wattanawongpitak N, Yuan Y, Junji T. Effect of flowable composite on cavity wall adaptation of composite restorations and mechanical properties. Adhes Dent 2004; 22 : 79-86.

16) Wattanawongpitak N, Yoshikawa T, Burrow MF, Tagami J. Effect of bonding system and composite type on adaptation of different C-factor restorations. Dent Mater J 2006; 25: 4550.

17) Belli S, Dönmez N, Eskitaşcioğlu G. The effect of c-factor and flowable resin or fiber use at the interface on microtensile bond strength to dentin. J Adhes Dent 2006; 8: 247-253.

18) Yoshikawa Y, Wattanawongpitak N, Tagami J. Correlation between bond strength and cavity wall adaptation. Jpn J Conserv Dent 2009; 46: 441-445.

19) Rupp NW. Clinical placement and performance of composite resin restorations. J Dent Res 1979; 58: 1551-1557.

20) Versluis A, Douglas WH, Cross M, Sakaguchi RL. Does an incremental filling technique reduce polymerization shrinkage stresses? J Dent Res 1996; 75: 871-878.

21) Yoshikawa Y, Sano H, Tagami J. Effect of cavity configuration on bond strength to floor dentin: a role of C-factor on dentin bonding. Adhes Dent 1996; 14: 43-49.

22) Kato H. Relationship between the velocity of polymerization and adaptation to dentin cavity wall of light-cured composite. Dent Mater J 1987; 6: 32-37.

23) Shimomura H. Photochemical studies on composite resins cured by visible light. Dent Mater J 1987; 6: 9-27.

24) Uno S, Asmussen E. Marginal adaptation of a restorative resin polymerized at reduced rate. Scand J Dent Res 1991; 99: 440-444.

25) Reinhardt K-J. Der einflußder lichtquelle auf die randständigkeit von kompositfüllungen. Dtsch Zahnärztl Z 1992; 46: 132-133.

26) Unterbrink GL, Muessner, R. Influence of light intensity on two restorative systems. J Dent 1995; 23: 183-189.

27) Mehl A, Hickel R, Kunzelmann KH. Physical properties and gap formation of light-cured composites with and without 'softstart-polymerization'. J Dent 1997; 25: 321-330.

28) Yoshikawa T, Burrow MF, Tagami J. The effects of bonding system and light curing method on reducing stress of different C-factor cavities. J Adhes Dent 2001; 3: 177-183.

29) Yoshikawa T, Burrow MF, Tagami J. The effects of light curing method and irradiation time on marginal sealing and cavity wall adaptation of resin composite restorations. Am J Dent 2003; 16: 63A-67A.

30) Ikeda T, Uno S, Tanaka T, Kawakami S, Komatsu H, Sano H. Microtensile bond strength to enamel and its relation to enamel prism orientation. Am J Dent 2002; 15: 109-113.

31) Øilo G, Jørgensen KD. Effect of beveling on the occurrence of fractures in the enamel surrounding composite resin fillings. J Oral Rehabil 1977; 4: 305-309.

32) Nishimura K, Ikeda K, Yoshikawa T, Otsuki M, Tagami J. Effect of various grit burs on marginal integrity of resin composite restorations. J Med Dent Sci 2005; 52: 9-15.

33) Staninec M, Mochizuki A, Tanizaki K, Fukuda K, Tsuchitani Y. Interfacial space, marginal leakage, and enamel cracks around composite resins. Oper Dent 1986; 11: 14-24.

34) Prati C, Chersoni S, Cretti L, Mongiorgi R. Marginal morphology of Class $\mathrm{V}$ composite restorations. Am J Dent 1997; 10: 231-236.

35) Sano H, Shono T, Takatsu T, Hosoda H. Microporous dentin zone beneath resin-impregnated layer. Oper Dent 1994; 19: 59-64.

36) Thompson VP, Williams EF, Baily WJ. Dental resins with reduced shrinkage during hardening. J Dent Res 1979; 58: 1522-1532.

37) Yoshikawa T, Morigami M, Sadr A, Tagami J. Acceleration of curing of resin composite at the bottom surface using slowstart curing methods. Dent Mater J 2013; 32: 999-1004.

38) Koran P, Kürschner R. Effect of sequential versus continuous irradiation of a light-cured resin composite on shrinkage, viscosity, adhesion, and degree of polymerization. Am J Dent 1998; 11: 17-22.

39) Sakaguchi RL, Berg, HX. Reduced light energy density decreases post-gel contraction while maintaining degree of conversion in composites. J Dent 1998; 26: 695-700.

40) Inokoshi S, Burrow MF, Kataumi M, Yamada T, Takatsu T. Opacity and color changes of tooth-colored restorative materials. Oper Dent 1996; 21: 73-80.

41) Inokoshi $\mathrm{S}$. Color adaptation of tooth-colored restorative materials. Dent Outlook 1996; 88: 786-821. 